\title{
Microvesicles isolated from 5-azacytidine- and-resveratrol-treated mesenchymal stem cells for the treatment of suspensory ligament injury in horse-a case report
}

\author{
Katarzyna Kornicka-Garbowska ${ }^{1,2}$, Rafał Pędziwiatr ${ }^{3}$, Paulina Woźniak², Katarzyna Kucharczyk ${ }^{1,2}$ and Krzysztof Marycz ${ }^{1,2,4^{*}}$
}

\begin{abstract}
Background: In athlete horses, suspensory ligament (SL) injuries are the most common cause of lameness. Healing of SL injury is still problematic, and even proper rehabilitation and pharmacological therapy do not guarantee returning to the initial performance level. In our previous studies, we have shown that a combination of 5-azacytidine (AZA) and resveratrol (RES) exerts beneficial, rejuvenating effects on metabolic syndrome derived adipose-derived stem cells (ASCs). Thus, in the presented research, we investigate whether not only rejuvenated ASC but also microvesicles (MVS AZARES $_{\text {S }}$ secreted by them possess enhanced regenerative properties in SL injury.
\end{abstract}

Methods: In the presented study, a 6-year-old Dutch Warmblood gelding, working in jumping, was diagnosed with SL injury using ultrasonography, Doppler, real-time elastography and thermography. As a therapeutic strategy, the affected animal was treated with extracellular microvesicles derived from ASC treated with the combination of 5-azacytydine (AZA) and resveratrol (RES) (MVS SZZARESS $_{\text {. }}$.

Results: First, anti-apoptotic effects of MVS AZA/RES $_{\text {were }}$ tested in co-culture with metabolic syndrome derived ASC. The proliferation of cells and expression of pro-apoptotic genes were investigated. Then, MVs AZA/RES were injected directly into the injured SL of the Dutch Warmblood gelding. In vitro assays revealed that MVS AZA/RES enhance the proliferation of ASC and exert an anti-apoptotic effect. In the affected horse, the application of $M V_{\text {SAZARES }}$ resulted in increased lesion filling and improvement of angiogenesis and elasticity in injured tissue.

Conclusions: As MVS AZA/RES mimic several of the biological actions exerted by ASC, they have become an alternative for stem cell-based therapies and can be effectively applied for the treatment of SL injury in horses.

Keywords: Microvesicles, Suspensory ligament, Horse, Injury

\section{Background}

Musculoskeletal injuries are especially common in human athletes who train sprint or jumping [1]. Similar phenomenon occurs in sport horses as they are at substantial risk for impact injuries or overexertion. In consequence, local muscle or tendon trauma occurs leading to poor performance and lameness. In horses, muscle tissue represents over $50 \%$ of bodyweight; thus, its demand for energy and cardiac

\footnotetext{
* Correspondence: krzysztofmarycz@interia.pl

'Department of Experimental Biology, Wroclaw University of Environmental and Life Sciences, Norwida 27B street, A7 building, 50-375 Wroclaw, Poland ${ }^{2}$ International Institute of Translational Medicine, Malin, Jesionowa 11, 55-114 Wisznia Mała, Poland

Full list of author information is available at the end of the article
}

output during exercise is high [2]. Factors predisposing for injuries to list are pre-existing lameness or injury, early season competition and lack of warm-up. Among diagnostic techniques, ultrasonography (USG) is recognized as a useful imaging procedure [3] in which muscle or tendon enlargement and loss of normal echogenicity consistent with fibre disruption can be noticed in acute injuries. Another noninvasive procedure is thermography which enables the pictorial representation of the surface temperature of an object allowing for visualization of inflammatory changes [4]. Additionally, elastography-ultrasound technique allows to detect and measure tissue strain, providing valuable information regarding equine tendon, muscle and ligament injuries

(c) The Author(s). 2019 Open Access This article is distributed under the terms of the Creative Commons Attribution 4.0 International License (http://creativecommons.org/licenses/by/4.0/), which permits unrestricted use, distribution, and 
[5]. Repeated injury to certain muscle group may result in fibrosis and ossification, finally contributing to mechanical lameness. Horses affected with strains, depending on its severity, are provided with anti-inflammatory, muscle relaxants and non-steroidal drugs while exercise activity is reduced from days to months [6]. Among injuries, suspensory ligament (SL) damage in horses is the most common cause of lameness especially in athletic individuals in competing dressage. Ligament sprain leads to swelling, pain and heat. Interestingly, usually, the proximal aspect of the SL is affected [7]. Healing of SL injury is still problematic, and even proper rehabilitation does not guarantee returning to the initial performance level. Tendon is a tissue characterized by limited regeneration caused by the formation of scar tissue resulting from relatively low number of resident cells in relation to amount of matrix. One of the therapeutic approaches for tendon injuries is conservative management which includes cold applications, controlled exercises, eccentric tendon training and extracorporeal shockwave therapy [8]. In case of severe injuries, surgical therapy (fasciotomy) is recommended. New approaches are focused on the regenerative medicine and its tools. Application of platelet-rich plasma (PRP) and stem cell therapies is more and more common $[9,10]$.

Nowadays, mesenchymal stem cells (MSCs) are widely applied in both human and veterinary medicine. Due to their unique properties, e.g. multilineage differentiation and immunomodulatory action, MSCs have afforded great promise in the treatment of numerous diseases [11]. There are 344 registered clinical trials in different clinical trial phases aimed at investigating the potential of MSC therapy worldwide [12]. Since now, MSCs have been proved to be effective in the treatment of tissue injury, immune and musculoskeletal diseases and neurodegenerative disorders [13-15]. Although MSCs have a tendency to home to damaged tissue sites, their therapeutic mechanism probably is other than differentiation in particular cell type. It was shown that MSC transplantation promoted the regeneration of skeletal muscle in a rat injury model; however, cells did not differentiate into myofibers indicating that distinct mechanism is responsible for therapeutic outcome [16].

Accumulating body of evidence has revealed that therapeutic benefits of MSC mainly depend on their ability to secrete a wide range of trophic factors. It was demonstrated that the paracrine activity of those cells can be utilized in the treatment of multiple disorders including liver, kidney, lung and myocardial injuries [13]. It was showed that MSC secrete a wide range of growth factors including vascular endothelial growth factor (VEGF), basic fibroblast growth factors (bFGF), hepatocyte growth factor (HGF), insulin-like growth factor 1 (IGF-1), interleukin 6 (IL-6) and chemokine (C-C motif) ligand 2 (CCL-2) [17]. Most of them act as key mediators in angiogenesis, regeneration and prevention of cell apoptosis. These proteins are secreted as a cargo in extracellular microvesicles (MVs) and exosomes. MVs are membrane-covered vesicles of various shapes with a diameter varying between 50 to $1000 \mathrm{~nm}$ and more, formed by budding from the plasma membrane [18]. What is more, not only cytokines and growth factors can be transferred within MVs but also messenger RNA (mRNA), lipids, ribosomal RNA, siRNA and microRNA (miRNA) [12]. Pro-regenerative functions of MVs were proved in several tissues, including the kidney, heart, liver, nervous tissues, lung and muscles [19]. Obtained results indicated that MV functions are similar to those of MSCs-they improve the regeneration process, suppress inflammation and modulate immune response. Nowadays, MVs are of great interest in the scope of regenerative medicine as they can pave the way for the development of cell-free therapies. Currently, the most common method of MV manufacturing in the laboratory is ultracentrifugation of MSC culture medium [20]. In order to obtain a great amount of MVs, cells are cultured under certain distress as MVs are released with their cargo to combat stressful condition [21]. Interestingly, MV cargo can be modulated by the application of certain stress-inducing factor [22]. What is more, MV content strongly depends on cytophysiological properties of MSC they are obtained from [23-25]. Our previous studies have shown that a combination of 5-azacytydine (AZA) and resveratrol (RES) reverses aged phenotype of MSC isolated from equine metabolic syndrome diagnosed animals (MSC-EMS) [26-28]. In consequence, those rejuvenated cells were characterized by an increased proliferation rate, reduced apoptosis and enhanced synthesis of MVs. Furthermore, AZA/RES diminished oxidative stress and improved mitochondrial condition and dynamics in those cells reversing degenerative changes caused by EMS-associated systemic inflammation [27, 29]. In this report, we decided to analyse the properties of MVs isolated from MSC-EMS and test whether the combination of AZA/RES may become a factor able to enrich MV cargo with proregenerative proteins. As AZA/RES strongly modulates metabolism of MSC, we hypothesized that naturally it also regulates the amount and cargo of secreted MVs.

Since now, MVs have shown much promise and benefits-due to their physiochemical stability in the body, non-immunogenic character and unique cargo, they can become alternative for stem cell-based therapies [30]. It was proved that MSC-derived exosomes accelerate muscle regeneration via promotion of myogenesis and angiogenesis, mediated by miRNAs (e.g. miR-494) [31], which supports their application in orthopaedics. In the presented case, taking into consideration the beneficial effects of AZA/RES on aged MSC, we decided to 
investigate the clinical utility of MVs derived from MSCEMS treated with these substances. For that reason, MVs were injected twice locally into injured suspensory ligament of a horse athlete.

\section{Methods}

All reagents used in the study were purchased from Sigma Aldrich Poland unless indicated otherwise.

\section{Isolation and culture of ASC}

Horses from which adipose tissue was collected were characterized in our previous study [32]. Animals from which samples were collected were divided into two groups: diagnosed with equine metabolic syndrome (EMS) and healthy (CTRL). ASCs were isolated in accordance with the procedure described before [29]. Briefly, adipose tissue was minced and incubated with 1 $\mathrm{mg} / \mathrm{ml}$ solution of collagenase type I. After centrifugation, the remaining pellet was re-suspended in culture media-Dulbecco's modified Eagle's medium (DMEM) low glucose supplemented with $10 \%$ of foetal bovine serum (FBS) and $1 \%$ of penicillin-streptomycin (PS) solution. The media were changed every 2 days. After reaching 90\% confluence, cells were passaged with TrypleExpress (Life Technologies). In order to isolate MVs, cells were passaged three times. When cells reach $80 \%$ confluence, cells were cultured in the presence of $0.5 \mu \mathrm{M}$ of AZA and $0.05 \mu \mathrm{M}$ of RES. After $24 \mathrm{~h}$, the medium supplemented with AZA/RES was exchanged for serum-free DMEM with $1 \%$ PS. After $24 \mathrm{~h}$, serumfree medium was collected for MV isolation.

\section{MV isolation}

Serum-free medium was collected from AZA/RES-treated ASC isolated from EMS individuals, in order to isolate MVs. MVs were harvested in accordance with the protocol described previously by Szatanek et al. [33] - differential centrifugation/ultracentrifugation. Briefly, the medium was centrifuged at $300 \times g$ for $10 \mathrm{~min}, 2000 \times g$ for $10 \mathrm{~min}$ and $10,000 \times g$ for $30 \mathrm{~min}$ respectively. After each centrifugation, the supernatant is transferred to a new tube while the pellet discarded. The pellet from the last centrifugation was re-suspended in sterile Hank's balanced salt solution (HBSS) as it consists of MV fraction. Those MVs were applied in in vitro and in vivo part of the study and are described in the figures as $\mathrm{MVs}_{\mathrm{AZA} / \mathrm{RES}}$.

\section{Evaluation of cellular proliferation}

Growth kinetics of ASCs was examined using a resazurin assay kit (TOX8), following the manufacturer's instructions as previously described [27]. To perform the assay, cells were seeded in 24-well plates at an initial concentration of $2 \times 10^{4}$ per well. The next day, after cells attached, different concentrations of as $\mathrm{MVs}_{\mathrm{AZA} / \mathrm{RES}}$ were added to the wells. After $24 \mathrm{~h}$ of culture, the medium was exchanged for DMEM low glucose supplemented with $10 \%$ of TOX8, and after 120 min of incubation with the dye, the first measurement was performed. The absorbance of the supernatants was measured at a wavelength of $600 \mathrm{~nm}$ for resazurin, and $690 \mathrm{~nm}$ reference wavelength (Epoch, BioTek). Measurements were performed after 24, 48, 72 and $96 \mathrm{~h}$ of culture. DNA synthesis was investigated by measuring the incorporation of 5-bromo-2-deoxyuridine (BrdU) into cellular DNA with BrdU Cell Proliferation ELISA Kit (Abcam) in accordance with the manufacturer's protocol. In this experiment, cells were pre-treated with $25 \mu \mathrm{g} / \mathrm{ml}$ $\mathrm{MVs}_{\mathrm{AZA} / \mathrm{RES}}$ for $24 \mathrm{~h}$. Next, cells were incubated with BrdU overnight at $37^{\circ} \mathrm{C}$. The incorporation of BrdU was evaluated by incubation with anti-BrdU monoclonal antibody. Colour reaction was developed using 3,3,5,5tetramethylbenzidine (TMB). Signal intensity was measured at a wavelength of 450/550 nm (Epoch; BioTek).

\section{TUNEL staining}

To perform the assay, cells were pre-treated with $25 \mu \mathrm{g} /$ $\mathrm{ml} \mathrm{MVs}_{\mathrm{AZA} / \mathrm{RES}}$ for $24 \mathrm{~h}$. DNA fragmentation was detected using TUNEL Assay Kit-BrdU-Red (Abcam, ab66110) in accordance with the manufacturer's instructions. Nuclei were counterstained with diamidino-2phenylindole (DAPI; 1:1000 in HBSS). Cells were observed and imaged using an epifluorescence microscope (AxioObserverA1; Zeiss).

\section{Quantitative real-time reverse transcription polymerase chain reaction (qPCR)}

Cells were homogenized by TriReagent ${ }^{\circ}$, and total RNA was isolated using the phenol-chloroform method as previously described by Chomczynski and Sacchi [34]. cDNA synthesis and qPCR were performed as described previously [26] using Tetro cDNA Synthesis Kit (Bioline) and SensiFast SYBR \& Fluorescein Kit (Bioline) respectively. Primer concentration in each reaction equalled to $500 \mathrm{nM}$ and their sequences are listed in Table 1. The average fold change in the gene expression of experimental cultures was compared with control cultures and calculated by the 2-DDCt method in relation to the housekeeping gene-GAPDH.

\section{Case description}

The study was performed after an approval by the Local Ethics Committee in Wroclaw, Poland (84/2018). The patient was a 6-year-old Dutch Warmblood gelding, working in jumping (up to $1.1 \mathrm{~m}$ ). The animal was diagnosed with lameness caused by suspensory ligament injury in the right forelimb. Six days after the accident, ultrasonography (USG), including histogram analysis, real-time elastography (RTE), and Doppler ultrasound 
Table 1 Primer sequences

\begin{tabular}{lllc}
\hline Gene & Primer & Sequence 5'-3' & Amplicon length (bp) \\
\hline p53 & F: & TACTCCCCTGCCCTCAACAA & 252 \\
& R: & AGGAATCAGGGCCTTGAGGA & \\
BAX & F: & GCCAGCAAATTGTGCTCAA & 260 \\
& R: & AGCAGTCACTTCCATGGCTC & \\
BCL-2 & F: & TTCTITGAGTTCGGTGGGT & 164 \\
& R: & GGGCCGTACAGTTCCACAA & \\
GAPDH & F: & GATGCCCCAATGTTTTGA & 250 \\
& R: & AAGCAGGGATGATGTTCTGG & \\
\hline
\end{tabular}

p53 tumour suppressor $\mathrm{p} 53$; $B A X \mathrm{BCl}$-2-associated $\mathrm{X}$ protein; $B C L-2 \mathrm{~B}$ cell lymphoma 2; GAPDH glyceraldehyde-3-phosphate dehydrogenase

measurements (SamsungHM70) of both forelimbs, was performed to evaluate the injured region. A complete examination of the SL was performed during each ultrasound examination with both transverse and longitudinal scans. Prior to thermography (Flir T335), the skin in the injury area was shaved. Seven days after injury, a USG-guided injection of $\mathrm{MVs}_{\mathrm{AZA} / \mathrm{RES}}$ directly into the injury site was performed. After 9 months of the first injection, in the same time, swelling in the proximallateral side of the right forelimb in the middle of the cannon was also noted. The horse was injected the second time with $\mathrm{MVs}_{\mathrm{AZA} / \mathrm{RES}}$. The first clinical evaluation was performed after 10th while the second clinical evaluation after 12th month of the first $\mathrm{MV}_{\mathrm{AZA} / \mathrm{RES}}$ injection. The injury of SL is shown in Fig. 1 while the timeframe of the experiment in Fig. 2.

\section{Statistics}

All experiments were performed at least in three replicates. Differences between experimental groups were estimated using the un-paired $t$ test (Prism5.04; GraphPad Software, La Jolla, CA, USA). Data normality was assessed in all groups by the Shapiro-Wilk test. Differences with probability of $p<0.05$ were considered significant. Results were presented as mean and standard deviation (SD).

\section{Results}

$M \mathrm{MS}_{\mathrm{AZA} / \mathrm{RES}}$ exert beneficial effects on $\mathrm{ASC}_{\mathrm{EMS}}$

Different concentrations of $\mathrm{MVs}_{\mathrm{AZA} / \mathrm{RES}}$ were tested in the co-culture with ASC isolated from EMS individuals (Fig. 3a). For further experiments, the most beneficial concentration, $25 \mu \mathrm{g} / \mathrm{ml}$, was applied. BrdU assay (Fig. 3b) confirmed that $\mathrm{MVs}_{\mathrm{AZA} / \mathrm{RES}}$ enhance ASC proliferation.

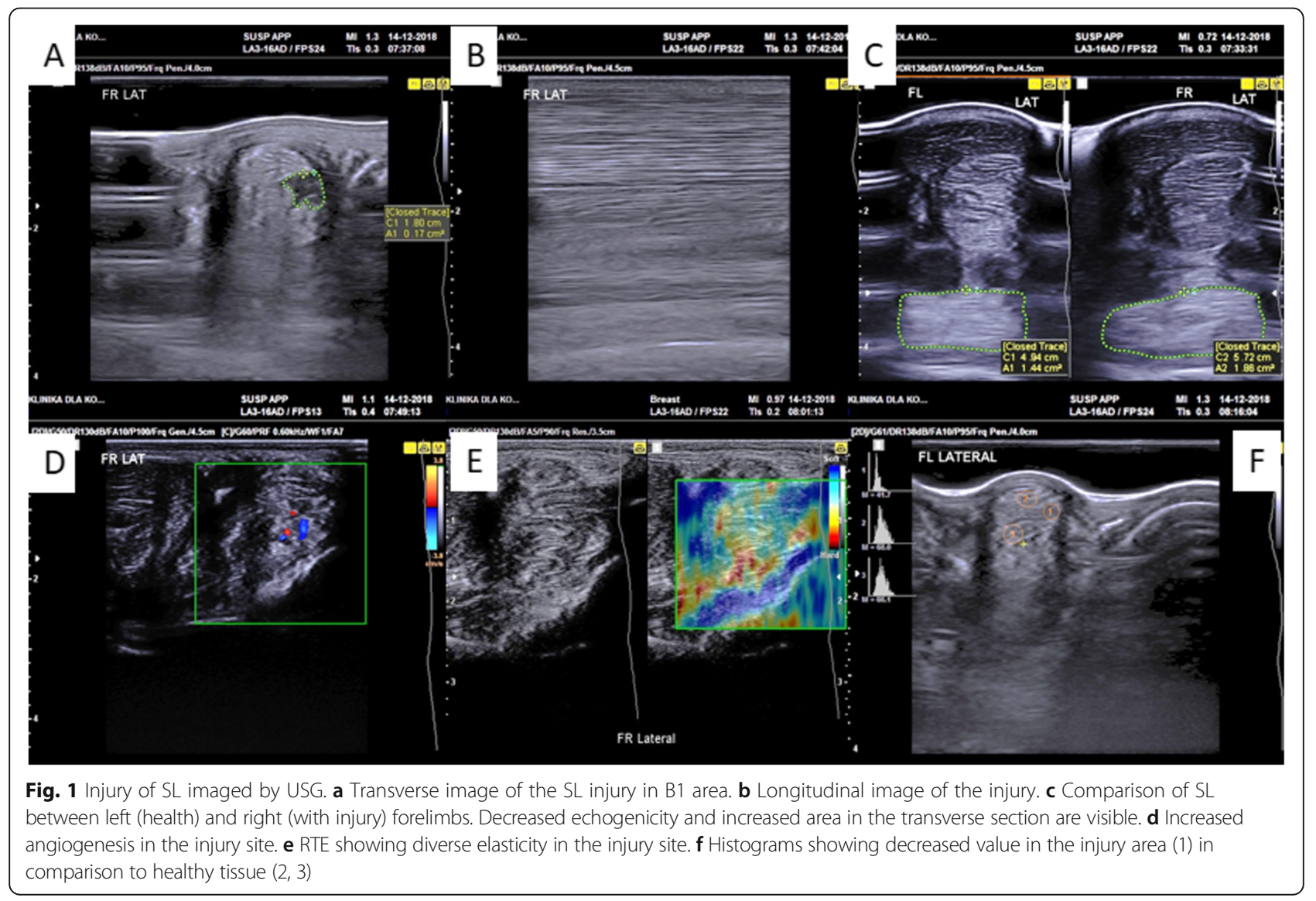




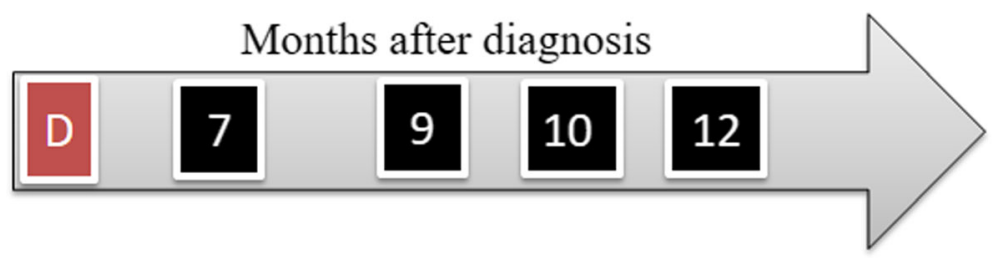

Fig. 2 Timeframe of the study. D, diagnosis of SL in jury in right forelimb, week after $\mathrm{MVS}_{\text {AZARES }}$ injection; 7, horse back to training; 9, swelling noted in the proximal-lateral side of the right forelimb in the middle of the cannon, second MVsAZA/RES injection; 10, first clinical evaluation; 12 , second clinical evaluation

\section{$M$ MS $_{\text {AZA/RES }}$ exert anti-apoptotic effects on ASC $\mathrm{EMS}_{\mathrm{E}}$}

TUNEL staining (Fig. 4a) revealed that MVs duced the number of dead cells. What is more, $\mathrm{MV}_{\mathrm{A}}$ ZA/RES treatment reduced the expression of BAX (Fig. 4b) and p53 (Fig. 4c) but enhanced the expression of anti-apoptotic BCL-2 (Fig. 4d).

\section{Clinical evaluation after $\mathrm{MV}_{\mathrm{AZA} / \mathrm{RES}}$ injection}

Following the injection, the horse showed any adverse reactions. The first examination demonstrated an early clinical improvement in the horse. Initiation of lesion filing with fibrous tissue was observed in transverse (Fig. 5a) longitudinal (Fig. 5b) images. An increased histogram value was observed in the injury site (Fig. 5c). An enhanced vascularization (Fig. 5d) and decreased elasticity (Fig. 5e) of the injury site resembling surrounding tissues were observed. Thermography revealed that an increased temperature in the right forelimb indicates an enhanced angiogenesis after MV injection (Fig. 5f).

In the second examination, transverse images of the injured SL site (Fig. 6a) revealed slightly increased echogenicity and formation of scar tissue separated from surrounding tissues with hypoechogenic fragments. Lesion filling on longitudinal image (Fig. 6b) and increased histograms of varying values between healthy and injured tissue (Fig. 6c) in the injury site were observed as well. Moderate blood supply in SL (Fig. 6d) and moderate differences of elasticity (Fig. 6e) were observed. Thermography showed no pathological changes in the injury site (Fig. 6f).

\section{Discussion}

Multiple reports, including our own, have indicated that MSC therapeutic potential depends on several factors, including patients' age, lifestyle and health condition [23, 24, 35-37]. Our group has revealed for the first time that in horses diagnosed with equine metabolic syndrome (EMS), isolated ASC suffers from great impairment of their cytophysiological properties [32]. EMS is characterized by obesity, hyperinsulinemia and insulin resistance and frequently leads to the development of laminitis. The main cause of disease is a high-starch diet combined with the lack of physical activity. We have shown that, in vitro culture, ASC from EMS individuals displayed decreased proliferation rate, increased apoptosis and senescence together with mitochondria deterioration [32]. In our previous research, we have demonstrated that autophagy is a rescue mechanism in those cells allowing them to maintain at least a part of their "stemness" $[26,38]$. That fact has a profound effect

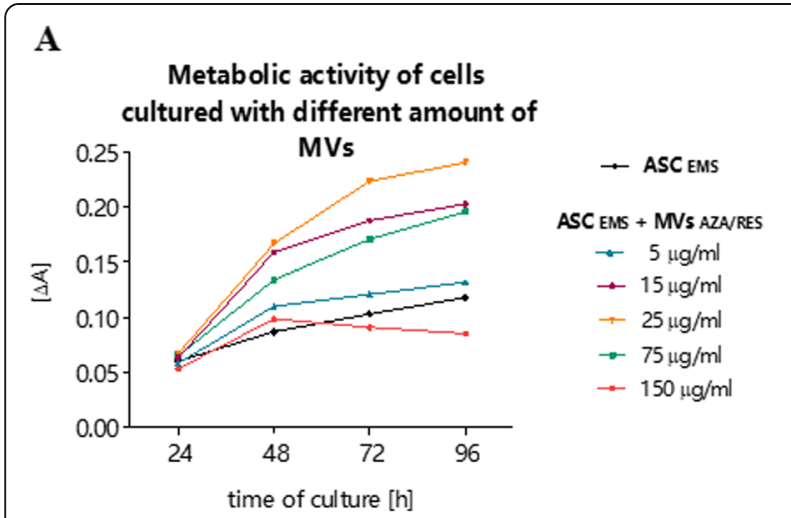

$\mathbf{B}$

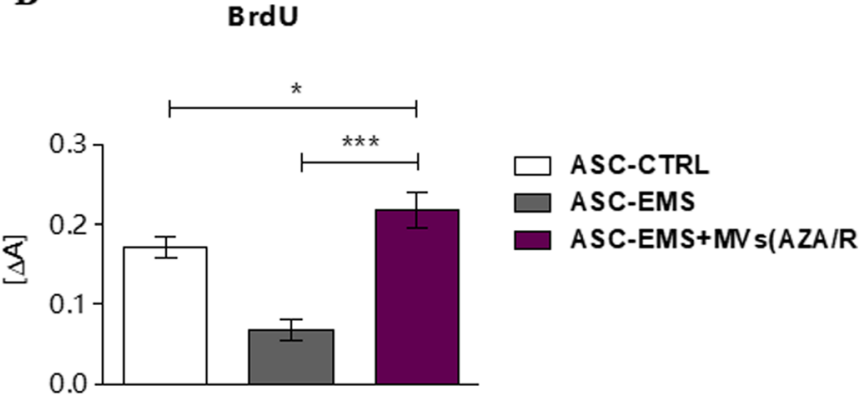

Fig. 3 MVs derived from AZA/RES-treated ASC enhance ASC EMS proliferation. Different dosages of MVs were added to ASC in order to investigate whether MVs work in a dose-dependent manner (a). The first measurement was performed after $24 \mathrm{~h}$ of co-culture. After that time, the medium was exchanged and cell proliferation was monitored till $96 \mathrm{~h}$ of culture. For further experiments, cells were cultured for $24 \mathrm{with} 25 \mathrm{\mu g} / \mathrm{ml}$ of MVs. $\mathrm{BrdU}$ analysis confirmed that selected concentration enhances cellular proliferation. Results are expressed as mean $\pm \mathrm{SD},{ }^{*} p<0.05 ;{ }^{* * *} p<0.001$ 


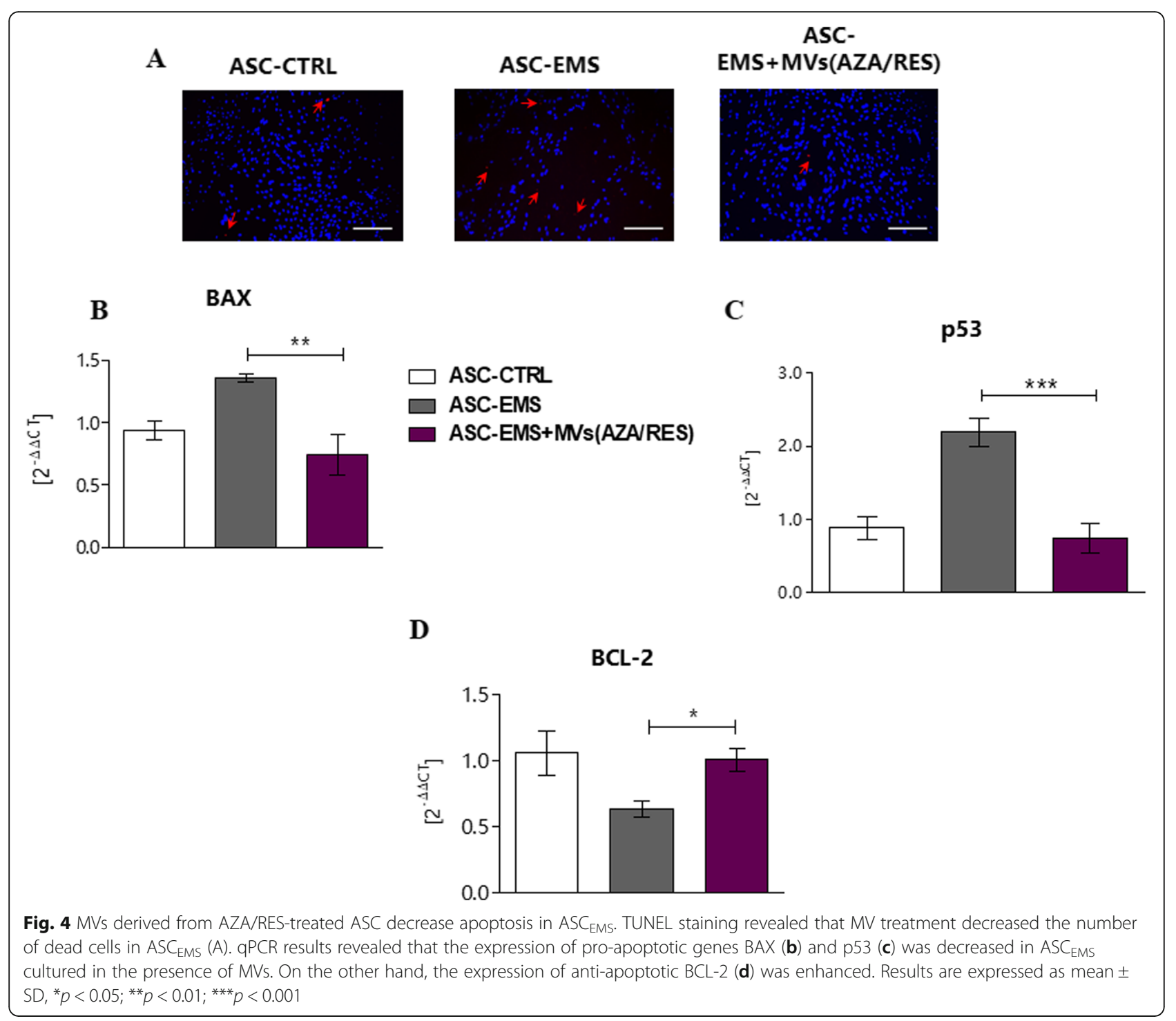

on regenerative medicine which utilizes stem cells for the treatment of different disorders including musculoskeletal injuries. As autologous stem cell therapies are still most desirable, searching for innovative methods able to rejuvenate impaired cells before therapy is strongly recommended. Since now, it was showed that pre-incubation of ASC with certain chemicals, including algae extracts, vitamins and basic fibroblast growth factors, exerts beneficial effects on cell metabolism [24, 3941]. In our recent research, we have demonstrated that the combination of AZA and RES rejuvenate EMS derived ASC by inhibition of mitochondrial fission [27, 29]. Treated cells were characterized by an increased proliferation rate, reduce apoptosis and senescence, improvement of mitochondria metabolism and enhanced secretion of MVs. In the presented study, we decided to investigate the therapeutic potential of MVs derived from these rejuvenated cells for the treatment of muscle injury in a horse. As MVs are immune privileged, we decided to perform allogenic therapy, using MVs obtained from our previous experiments-MVs were harvested from ASC isolated from EMS individuals treated in vitro with AZA/RES. Our hypothesis was that similar to rejuvenated ASC, their MVs will be characterized by enhanced bioactivity.

As MVs were shown to mimic the beneficial effects of MSC, they are thought to be at least partially responsible for their regenerative properties. In vitro experiments revealed that MVs derived from AZA/RES-treated cells stimulated the proliferation rate of ASC in co-culture in a dose-dependent manner. Similarly, Bruno et al. revealed that MSC-derived MVs increased the proliferation rate of tubular epithelial cells after in vitro injury [42]. What is more, they decreased apoptosis in EMS derived ASC. TUNEL staining indicated that MV treatment reduced the number of dead cells in culture, while 


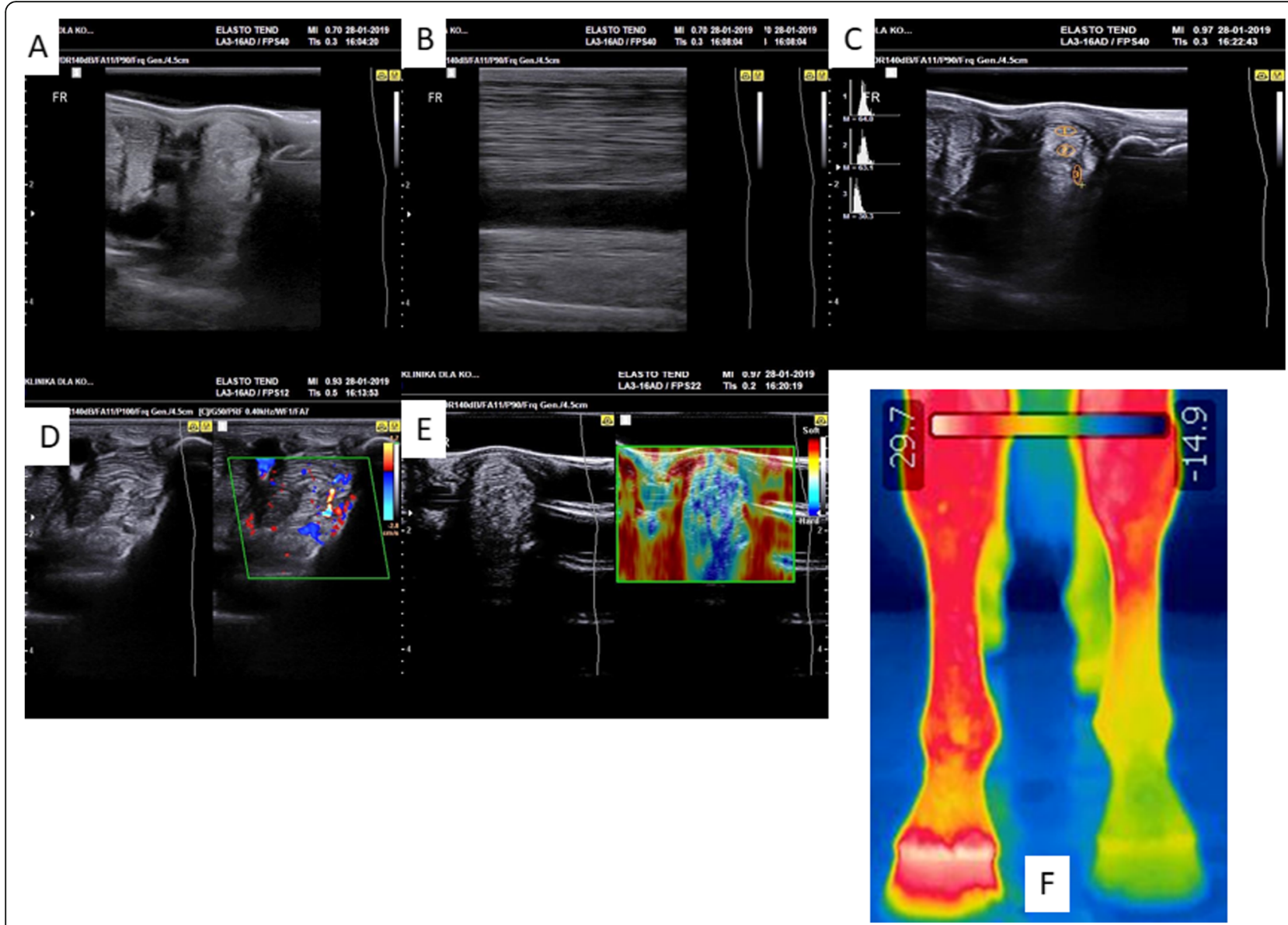

Fig. 5 Clinical evaluation after the first MV $\mathrm{V}_{\text {AZARES }}$ injection. The resolution of a focal lesion within the $S L$ of the right forelimb. a Initiation of lesion filling - transverse image. $\mathbf{b}$ Lesion filling on a longitudinal image. $\mathbf{c}$ Increased histogram value in the injury site. $\mathbf{d}$ Transverse image of enhanced vascularization. e Decreased elasticity of the injury site resembling surrounding tissues. $\mathbf{f}$ Increased temperature in the right forelimb indicates an enhanced angiogenesis after MV injection

qPCR results revealed a decreased expression of proapoptotic genes, e.g. p53 and BAX, while anti-apoptotic gene $\mathrm{Bcl}-2$ expression was enhanced. In a cisplatininduced lethal model of acute kidney injury, several injections of MVs derived from MSC increased antiapoptotic gene expression, including Bcl-2, in tubular epithelial cells [43]. Similar protective effects of MVs were shown in a model of renal ischaemia/reperfusion injury where MVs inhibited apoptosis and stimulated cellular proliferation [44]. On the other hand, Herrera et al. demonstrated that in human and rat hepatocytes, MVs enhanced proliferation and decreased apoptosis through mRNA shuttled into recipient cells [45].

Due to their frequent and demanding physical activity, sport horses suffer from great mechanical overload of musculoskeletal system which makes them especially prone for traumatization and injuries. Especially common is injury of the suspensory ligament (SL) which contributes to pain and lameness. Since now, regenerative properties of MVs were mainly studied in different animal models of tissue injury [42, 44]. In the presented study, we decided to inject MVs from rejuvenated ASC into injured suspensory ligament in order to decrease inflammation, enhance angiogenesis and trigger a regenerative response of resident cells. Previous studies as a therapeutic approach for SL injuries utilized platelet-rich plasma (PRP), cellular bone marrow or tenogenically induced allogeneic peripheral blood mesenchymal stem cells $[10,46]$. In the study performed by Vandenberghe et al. [47], allogeneic tenogenically induced peripheral blood-derived MSCs combined with PRP were utilized for the treatment of a proximal SL injury with positive outcome. On the other hand, studies performed in vitro revealed that PRP and acellular bone marrow (ACB) increased the expression of cartilage oligomeric matrix protein (COMP) production in equine suspensory ligament fibroblasts (SLF) [46]. As equine ABM and PRP are rich in anabolic factors that promote matrix synthesis, their application to injured ligaments is also justified. Our report for the first time demonstrated the 


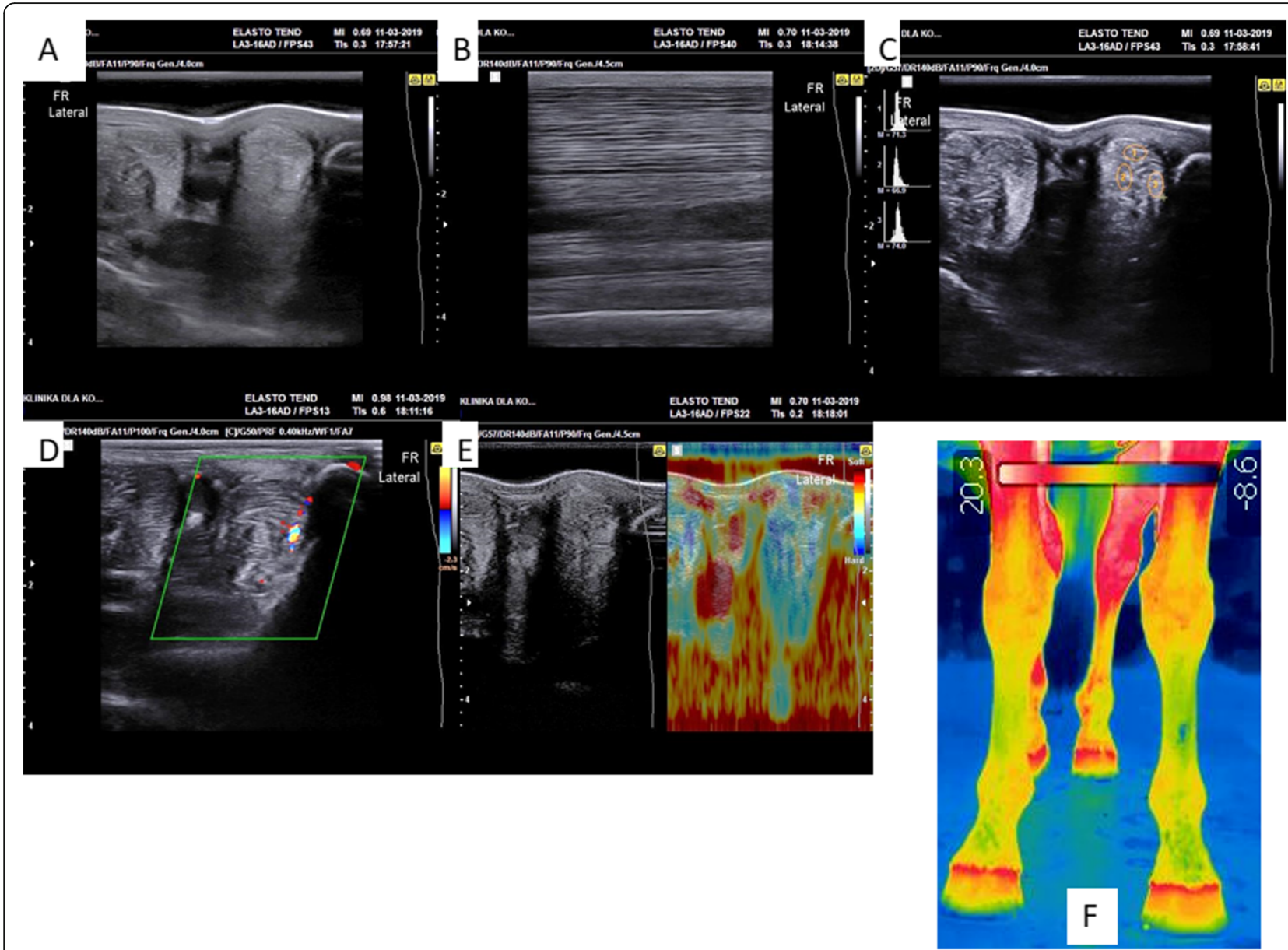

Fig. 6 Clinical evaluation after the second MV $\mathrm{V}_{\text {AZARES }}$ injection. a Transverse images of the injured SL site with a slightly increased echogenicity; the formation of scar tissue separated from surrounding tissues with hypoechogenic fragments can be observed. $\mathbf{b}$ Longitudinal image. $\mathbf{c}$ Histograms of varying values between healthy and injured tissue. $\mathbf{d}$ Moderate blood supply in SL. e Moderate differences of elasticity in SL. f Thermography showed no pathological changes

application of MSC-derived MVs for SL injury treatment. The obtained results correspond with the data obtained in the research mentioned above. SL ligament is a complex structure as it is composed of soft tissue and bone components. In the presented report, diagnosis was made by USG, Doppler, RTE and thermography. A strong limitation of our study is the lack of angiography which could bring more information about lesion severity. As MSCs were shown to form ectopic bone in the calcified area [48], the application of MVs for SL injury seems to be a safe and reasonable alternative. The first application of MVs resulted in an initiation of lesion filling with scar tissue, increased parallel fibre pattern and moderate diffuse decrease in echogenicity. What is more, we observed an increased temperature in the area of lesion which correlated with the increased angiogenesis in the injury site.

In recent years, regenerative medicine has focused on soluble factors released by MSC, including MVs. As
MVs mimic several of the biological actions exerted by MSC, they have become an alternative for stem cellbased therapies. Here, we proved for the first time the safe and effective application of MVs isolated from AZA/RES-treated cells for the treatment of suspensory ligament in athletic horse. Still, further research needs to be performed in order to fully understand the mechanism and therapeutic potential of these bioactive factors.

\section{Conclusions}

Here, we presented that $\mathrm{MVs}_{\mathrm{AZA} / \mathrm{RES}}$ exert rejuvenating effects in vitro as they enhanced cellular proliferation and decreased apoptosis. Beneficial effects of $\mathrm{MVs}_{\mathrm{A}}$ ZA/RES were confirmed in vivo for the treatment of SL injury in horse, as enhanced vascularization and healing were observed.

\section{Abbreviations}

ACB: Acellular bone marrow; ASCs: Adipose-derived stem cells: AZA: 5-

Azacytidine; bFGF: Basic fibroblast growth factors; CCL-2: Chemokine (C-C 
motif) ligand 2; COMP: Increased expression of cartilage oligomeric matrix protein; EMS: Equine metabolic syndrome; HGF: Hepatocyte growth factor; IGF-1: Insulin-like growth factor 1; IL-6: Interleukin 6 (IL-6); miRNA: MicroRNA mRNA: Messenger RNA; MSCs: Mesenchymal stem cells; MSC-EMS: MSC isolated from equine metabolic syndrome diagnosed animals; MVs: Microvesicles; MVs AZA/REs: Microvesicles derived from 5-azacytydine and resveratrol adipose-derived stem cells; PRP: Platelet-rich plasma; RES: Resveratrol; SL: Suspensory ligament; SLF: Equine suspensory ligament fibroblasts; USG: Ultrasonography; VEGF: Vascular endothelial growth factor

\section{Authors' contributions}

KK participated in the writing of the manuscript, experiment planning, cell culture and data analysis. RP participated in the in vivo part of the experiment, diagnosis and clinical examination and interpretation of the obtained result. PW participated in material collection and data interpretation. KK performed the molecular biology analysis and cell culture. KM designed and coordinated the study, wrote the manuscript and provided funding. All authors read and approved the final manuscript.

\section{Funding}

This research was supported by the National Science Centre, Poland, grant no. 2016/21/B/NZ7/01111 "Modulation mitochondrial metabolism and dynamics and tageting DNA methylation of adipose derived mesenchymal stromal stem cell (ASC) using RES and 5-azacytydin as a therapeutic strategy in the course of EMS."

\section{Availability of data and materials}

The datasets generated during and/or analysed during the current study are available from the corresponding author on reasonable request.

\section{Ethics approval and consent to participate}

The study was performed after an approval by the Local Ethics Committee in Wroclaw, Poland (84/2018).

\section{Consent for publication}

Not applicable.

\section{Competing interests}

The authors declare that they have no competing interests.

\section{Author details}

${ }^{1}$ Department of Experimental Biology, Wroclaw University of Environmental and Life Sciences, Norwida 27B street, A7 building, 50-375 Wroclaw, Poland. ${ }^{2}$ International Institute of Translational Medicine, Malin, Jesionowa 11, 55-114 Wisznia Mała, Poland. ${ }^{3}$ EQUI-VET Clinic for Horses, Stogniowice 55A, 32-100 Proszowice, Poland. ${ }^{4}$ Faculty of Veterinary Medicine, Equine Clinic-Equine Surgery, Justus-Liebig-University, 35392 Giessen, Germany.

\section{Received: 7 May 2019 Revised: 9 September 2019} Accepted: 23 October 2019 Published online: 18 December 2019

\section{References}

1. Kollias-Baker C. Therapeutics of musculoskeletal disease in the horse. Vet Clin North Am Equine Pract. 1999;15:589-602.

2. Kearns CF, McKeever KH, Abe T. Overview of horse body composition and muscle architecture: implications for performance. Vet J. 2002;164:224-34.

3. Davidson EJ. Lameness evaluation of the athletic horse. Vet Clin North Am Equine Pract. 2018:34:181-91.

4. Eddy AL, Van Hoogmoed LM, Snyder JR. The role of thermography in the management of equine lameness. Vet J. 2001;162:172-81.

5. Tamura N, Nukada T, Kato T, Kuroda T, Kotoyori Y, Fukuda K, et al. The use of sonoelastography to assess the recovery of stiffness after equine superficial digital flexor tendon injuries: a preliminary prospective longitudinal study of the healing process. Equine Vet J. 2017:49:590-5.

6. Lutter JD, Schneider RK, Sampson SN, Cary JA, Roberts GD, Vahl Cl. Medical treatment of horses with deep digital flexor tendon injuries diagnosed with high-field-strength magnetic resonance imaging: 118 cases (2000-2010). J Am Vet Med Assoc. 2015;247:1309-18.

7. Clinical evaluation of intralesional injection of platelet-rich plasma for the treatment of proximal suspensory ligament desmitis in horses -
ScienceDirect. [cited 2019 Apr 26]. Available from: https://www sciencedirect.com/science/article/pii/S0737080614004729?via\%3Dihub

8. Thorpe CT, Clegg PD, Birch HL. A review of tendon injury: why is the equine superficial digital flexor tendon most at risk? Equine Vet J. 2010;42:174-80.

9. Geburek F, Gaus M, van Schie HTM, Rohn K, Stadler PM. Effect of intralesional platelet-rich plasma (PRP) treatment on clinical and ultrasonographic parameters in equine naturally occurring superficial digital flexor tendinopathies - a randomized prospective controlled clinical trial. BMC Vet Res. 2016 [cited 2019 Sep 9];12. Available from: https://www.ncbi. nlm.nih.gov/pmc/articles/PMC5015224/

10. Beerts C, Suls M, Broeckx SY, Seys B, Vandenberghe A, Declercq J, et al. Tenogenically induced allogeneic peripheral blood mesenchymal stem cells in allogeneic platelet-rich plasma: 2-year follow-up after tendon or ligament treatment in horses. Front Vet Sci. 2017 [cited 2019 Sep 9];4. Available from: https://www.ncbi.nlm.nih.gov/pmc/articles/PMC5622984/

11. Cislo-Pakuluk A, Marycz K. A promising tool in retina regeneration: current perspectives and challenges when using mesenchymal progenitor stem cells in veterinary and human ophthalmological applications. Stem Cell Rev. 2017:13:598-602.

12. Akyurekli C, Le Y, Richardson RB, Fergusson D, Tay J, Allan DS. A systematic review of preclinical studies on the therapeutic potential of mesenchymal stromal cell-derived microvesicles. Stem Cell Rev and Rep. 2015;11:150-60.

13. Wei X, Yang X, Han Z, Qu F, Shao L, Shi Y. Mesenchymal stem cells: a new trend for cell therapy. Acta Pharmacol Sin. 2013;34:747-54.

14. Fiore EJ, Mazzolini G, Aquino JB. Mesenchymal stem/stromal cells in liver fibrosis: recent findings, old/new caveats and future perspectives. Stem Cell Rev and Rep. 2015;11:586-97.

15. Lindroos B, Suuronen R, Miettinen S. The potential of adipose stem cells in regenerative medicine. Stem Cell Rev. 2011;7:269-91.

16. Natsu K, Ochi M, Mochizuki $Y$, Hachisuka H, Yanada S, Yasunaga Y. Allogeneic bone marrow-derived mesenchymal stromal cells promote the regeneration of injured skeletal muscle without differentiation into myofibers. Tissue Eng. 2004;10:1093-112.

17. Chamberlain G, Fox J, Ashton B, Middleton J. Concise review: mesenchyma stem cells: their phenotype, differentiation capacity, immunological features, and potential for homing. Stem Cells. 2007:25:2739-49.

18. Ståhl A, Johansson K, Mossberg M, Kahn R, Karpman D. Exosomes and microvesicles in normal physiology, pathophysiology, and renal diseases. Pediatr Nephrol. 2019;34:11-30.

19. Panfoli I, Santucci L, Bruschi M, Petretto A, Calzia D, Ramenghi LA, et al. Microvesicles as promising biological tools for diagnosis and therapy. Expert Rev Proteomics. 2018;15:801-8.

20. Pashoutan Sarvar D, Shamsasenjan K, Akbarzadehlaleh P. Mesenchymal stem cell-derived exosomes: new opportunity in cell-free therapy. Adv Pharm Bull. 2016:6:293-9.

21. Choi W, Kwon S-J, Jin HJ, Jeong SY, Choi SJ, Oh W, et al. Optimization of culture conditions for rapid clinical-scale expansion of human umbilical cord blood-derived mesenchymal stem cells. Clin Transl Med. 2017;6:38.

22. Haraszti RA, Miller R, Stoppato M, Sere YY, Coles A, Didiot M-C, et al. Exosomes produced from 3D cultures of MSCs by tangential flow filtration show higher yield and improved activity. Mol Ther. 2018;26:2838-47.

23. Kornicka K, Marycz K, Tomaszewski KA, Marędziak M, Śmieszek A. The effect of age on osteogenic and adipogenic differentiation potential of human adipose derived stromal stem cells (hASCs) and the impact of stress factors in the course of the differentiation process. Oxid Med Cell Longev. 2015; 2015:309169.

24. Nawrocka D, Kornicka K, Szydlarska J, Marycz K. Basic fibroblast growth factor inhibits apoptosis and promotes proliferation of adipose-derived mesenchymal stromal cells isolated from patients with type 2 diabetes by reducing cellular oxidative stress. Oxidative Medicine and Cellular Longevity. 2017 [cited 2017 Jul 27]. Available from: https://www.hindawi.com/journals/ omcl/2017/3027109/ref/

25. Jumabay M, Moon JH, Yeerna $\mathrm{H}$, Boström Kl. Effect of diabetes mellitus on adipocyte-derived stem cells in rat. J Cell Physiol. 2015;230:2821-8.

26. Marycz K, Kornicka K, Marędziak M, Golonka P, Nicpoń J. Equine metabolic syndrome impairs adipose stem cells osteogenic differentiation by predominance of autophagy over selective mitophagy. J Cell Mol Med. 2016:20:2384-404

27. Kornicka K, Szłapka-Kosarzewska J, Śmieszek A, Marycz K. 5-Azacytydine and resveratrol reverse senescence and ageing of adipose stem cells via modulation of mitochondrial dynamics and autophagy. J Cell Mol Med. 2018. 
28. Kornicka K, Śmieszek A, Węgrzyn AS, Röcken M, Marycz K Immunomodulatory properties of adipose-derived stem cells treated with 5azacytydine and resveratrol on peripheral blood mononuclear cells and macrophages in metabolic syndrome animals. J Clin Med. 2018;7:383.

29. Marycz K, Kornicka K, Irwin-Houston JM, Weiss C. Combination of resveratrol and 5-azacytydine improves osteogenesis of metabolic syndrome mesenchymal stem cells. J Cell Mol Med. 2018;22:4771-93.

30. Cha JM, Shin EK, Sung JH, Moon GJ, Kim EH, Cho YH, et al. Efficient scalable production of therapeutic microvesicles derived from human mesenchymal stem cells. Sci Rep. 2018 [cited 2019 Sep 9];8. Available from: https://www. ncbi.nlm.nih.gov/pmc/articles/PMC5775399/

31. Nakamura Y, Miyaki S, Ishitobi H, Matsuyama S, Nakasa T, Kamei N, et al. Mesenchymal-stem-cell-derived exosomes accelerate skeletal muscle regeneration. FEBS Lett. 2015;589:1257-65

32. Marycz K, Kornicka K, Basinska K, Czyrek A. Equine metabolic syndrome affects viability, senescence, and stress factors of equine adipose-derived mesenchymal stromal stem cells: new insight into EqASCs isolated from EMS horses in the context of their aging. Oxidative Medicine and Cellular Longevity. 2016:2016:1-17.

33. Szatanek R, Baran J, Siedlar M, Baj-Krzyworzeka M. Isolation of extracellular vesicles: determining the correct approach (review). Int J Mol Med. 2015:36:11-7.

34. Chomczynski P, Sacchi N. Single-step method of RNA isolation by acid guanidinium thiocyanate-phenol-chloroform extraction. Anal Biochem. 1987; 162:156-9.

35. Stolzing A, Jones E, McGonagle D, Scutt A. Age-related changes in human bone marrow-derived mesenchymal stem cells: consequences for cell therapies. Mech Ageing Dev. 2008;129:163-73.

36. Kornicka K, Houston J, Marycz K. Dysfunction of mesenchymal stem cells isolated from metabolic syndrome and type 2 diabetic patients as result of oxidative stress and autophagy may limit their potential therapeutic use. Stem Cell Rev and Rep. 2018:1-9.

37. Bourebaba L, Röcken M, Marycz K. Osteochondritis dissecans (OCD) in horses - molecular background of its pathogenesis and perspectives for progenitor stem cell therapy. Stem Cell Rev and Rep. 2019 [cited 2019 Apr 4]; Available from: https://doi.org/10.1007/s12015-019-09875-6

38. Marycz K, Kornicka K, Grzesiak J, Śmieszek A, Szłapka J. et al. Macroautophagy and selective mitophagy ameliorate chondrogenic differentiation potential in adipose stem cells of equine metabolic syndrome: new findings in the field of progenitor cells differentiation. Oxid Med Cell Longev. 2016. [cited 2017 Jul 27]. Available from: https://www. hindawi.com/journals/omcl/2016/3718468/.

39. Kornicka K, Babiarczuk B, Krzak J, Marycz K. The effect of a sol-gel derived silica coating doped with vitamin $\mathrm{E}$ on oxidative stress and senescence of human adipose-derived mesenchymal stem cells (AMSCs). RSC Adv. 2016;6: 29524-37.

40. Nawrocka D, Kornicka K, Śmieszek A, Marycz K. Spirulina platensis improves mitochondrial function impaired by elevated oxidative stress in adiposederived mesenchymal stromal cells (ASCs) and intestinal epithelial cells (IECs), and enhances insulin sensitivity in equine metabolic syndrome (EMS) horses. Mar Drugs. 2017;15(8): 237.

41. Marycz K, Michalak I, Kocherova I, Marędziak M, Weiss C. The Cladophora glomerata enriched by biosorption process in $\mathrm{Cr}$ (III) improves viability, and reduces oxidative stress and apoptosis in equine metabolic syndrome derived adipose mesenchymal stromal stem cells (ASCs) and their extracellular vesicles (MV's). Mar Drugs. 2017;15(12):385.

42. Mesenchymal stem cell-derived microvesicles protect against acute tubular injury. - PubMed - NCBI. [cited 2019 Apr 26]. Available from: https://www. ncbi.nlm.nih.gov/pubmed/19389847

43. Microvesicles derived from mesenchymal stem cells enhance survival in a lethal model of acute kidney injury. - PubMed - NCBI. [cited 2019 Apr 26]. Available from: https://www.ncbi.nlm.nih.gov/pubmed/22431999

44. Microvesicles derived from human adult mesenchymal stem cells protect against ischaemia-reperfusion-induced acute and chronic kidney injury. PubMed - NCBI. [cited 2019 Apr 26]. Available from: https://www.ncbi.nlm. nih.gov/pubmed/21324974

45. Herrera MB, Fonsato V, Gatti S, Deregibus MC, Sordi A, Cantarella D, et al. Human liver stem cell-derived microvesicles accelerate hepatic regeneration in hepatectomized rats. J Cell Mol Med. 2010;14:1605-18.

46. Anabolic effects of acellular bone marrow, platelet rich plasma, and serum on equine suspensory ligament fibroblasts in vitro. - PubMed - NCBI. [cited
2019 Apr 26]. Available from: https://www.ncbi.n/m.nih.gov/pubmed/165 94543

47. Tenogenically induced allogeneic mesenchymal stem cells for the treatment of proximal suspensory ligament desmitis in a horse. [cited 2019 Apr 26]. Available from: https://www.ncbi.nlm.nih.gov/pmc/articles/PMC4672201/

48. Mesenchymal stem cells used for rabbit tendon repair can form ectopic bone and express alkaline phosphatase activity in constructs. - PubMed NCBI. [cited 2019 Apr 26]. Available from: https://www.ncbi.nlm.nih.gov/ pubmed/15304271/

\section{Publisher's Note}

Springer Nature remains neutral with regard to jurisdictional claims in published maps and institutional affiliations.

\section{Ready to submit your research? Choose BMC and benefit from:}

- fast, convenient online submission

- thorough peer review by experienced researchers in your field

- rapid publication on acceptance

- support for research data, including large and complex data types

- gold Open Access which fosters wider collaboration and increased citations

- maximum visibility for your research: over $100 \mathrm{M}$ website views per year

At BMC, research is always in progress.

Learn more biomedcentral.com/submissions 